\title{
Pipeline Life Extension and Integrity Management Based on Optimized Use of Above Ground Survey Data and Inline Inspection Results
}

\author{
A. Francis, M. McCallum, and C. Jandu
}

Andrew Francis \& Associates, UK

УДК 539.4

\section{Продление долговечности трубопроводов и меры по обеспечению их работоспособности, основанные на оптимизированном использовании результатов наземной диагностики и локальной инспекции}

\author{
А. Фрэнсис, М. Маккаллум, Ч. Джанду \\ “Эндрю Фрэнсис и партнеры”, Великобритания \\ Подробно описаны вероятностные методики, основаннье на обновлении данньх по Байесу и \\ расчете надежности конструкиий. Методики используются для оптилизации диагностичес- \\ ких осмотров и (или) частоты проведения локальних инспекций трубопроводов. Это гаранти- \\ рует экономичное решение проблем обеспечения работоспособности трубопроводов, про- \\ дления их долговечности или оптимизации давления в них. Суть предложенной методики и \\ особенности ее применения детально описаньл на различньх примерах.
}

Ключевые слова: трубопровод, вероятностные методики, надежность конструкции, долговечность, оптимизация.

\section{Nomenclature}

$\begin{array}{ll}a & - \text { corrosion defect depth } \\ a_{c} & - \text { critical corrosion defect depth } \\ a_{r} & - \text { depth of corrosion defect requiring repair } \\ p\left(a, t_{\text {age }} \mid K, t_{i}\right) & - \text { conditional defect depth distribution } \\ p_{0}\left(a, t_{\text {age }}\right) & - \text { defect depth distribution } \\ p_{0}(K) & - \text { growth rate distribution } \\ p_{0}\left(t_{i}\right) & - \text { initiation time distribution } \\ t & - \text { time } \\ t_{a g e} & - \text { age of pipeline } \\ t_{i} & - \text { initiation time } \\ E_{C} & - \text { expected number of corrosion defects } \\ E_{H} & - \text { expected number of coating holidays } \\ K & - \text { corrosion growth rate }\end{array}$




\begin{tabular}{ll}
\hline$N_{A}$ & - number of indications by survey only $A$ \\
$N_{B}$ & - number of indications by survey only $B$ \\
$N_{A B}$ & - number of indications by surveys $A$ and $B$ \\
$N_{C}$ & - number of corrosion defects \\
$N_{H}$ & - number of coating holidays \\
$P_{0}\left(a_{r}, t_{\text {age }}\right)$ & - probability of exceeding repair criteria \\
$V_{C}$ & - variance of number of corrosion defects \\
$V_{H}$ & - variance of number of coating holidays \\
$\alpha$ & - ratio of corrosion defects to coating holidays \\
$\phi_{A}$ & - probability of false indication of survey $A$ \\
$\phi_{B}$ & - probability of false indication of survey $B$ \\
$\zeta_{A}$ & - probability of detection of survey $A$ \\
$\zeta_{B}$ & - probability of detection of survey $B$
\end{tabular}

Introduction. Oil and gas pipelines have now been operating in many parts of the world for periods in excess of 40 , or in some places even 60 , years. Operation has largely been very successful with relatively few fatal accidents when compared with the operation of other types of hazardous equipment. However, due to the increasing age of pipelines, more rigorous inspection and maintenance regimes are becoming increasingly important to ensure that the existing safety record is increased or even improved.

There is a world-wide recognition that, in addition to other damage mechanisms, external corrosion can pose a serious threat to the integrity of buried onshore pipelines and the focus on methods to prevent corrosion failures is increasing. The primary means of preventing corrosion is the application of a protective coating prior to installation. However, it is well recognized that breaches in the coating do occur for several reasons and that the number of breaches can increase with time. For this reason, secondary measures are included such as the Cathodic Protection (CP) systems to mitigate the likelihood of corrosion growth when breaches occur. Even so, the effectiveness of CP systems is known to be variable and intermittent and external corrosion occur. In view of this, above ground surveys such as Direct Current Voltage Gradient (DCVG) and Close Interval Potential (CIPS) are periodically undertaken to identify areas of coating loss and locations of active corrosion, respectively. Additionally, in-line inspection (ILI) tools are used to detect the locations of actual metal loss. The objective of all surveys and inspections is to locate the presence of corrosion defects in a timely manner in order that repairs can be undertaken before failure occurs. Accordingly, excavations are performed at the most likely locations and if corrosion damage is present and exceeds some pre-determined criteria, a repair is performed.

The systems and activities described above are basic components of an integrity management plan (IMP). However, the effectiveness of the IMP depends on the frequency at which the surveys and inspections are undertaken and the reliability of the equipment used. Different combinations of surveys may be used with different frequencies. For instance, ILI is likely to be used less frequently than above ground surveys. Moreover, for a significant number of pipelines, ILI is not 
possible resulting in total reliance on above ground surveys. The integrity management process based on above ground surveys alone has become known as External Corrosion Direct Assessment (ECDA).

Irrespective of whether ILI, ECDA, or a combination of the two is used, it is important to ensure that frequencies at which the methods are employed are sufficient to ensure that risk of failure is acceptably low. The determination of the survey and inspection frequencies thus needs to take account of the reliability and accuracy of the tools and also the current condition of the pipeline. Probabilistic techniques are best suited to this purpose.

A full description of the method is provided and the application of the techniques is clearly illustrated through case studies.

Integrity management of high pressure oil and gas pipelines is recognized world-wide as the primary means of ensuring that the pipelines are operated safely.

In basic terms, integrity management involves

(i) a identification of the potential causes of damage to the pipe-wall;

(ii) a determination of the severity of each type of damage that can be tolerated without causing failure combined with and/or

(iii) a means of preventing the occurrence of damage;

(iv) a means of ensuring that if damage does occur it can be tolerated.

For onshore pipelines the potential causes of damage are generally the same world-wide and include external interference, external/internal corrosion, stress corrosion cracking and construction processes (welding). However, due to differences in operating environments and construction techniques the relative importance of these potential causes may differ across the globe.

Means for determining the severity of the damage that can be tolerated are available for all types of damage and models that may be used for this purpose appear in various design codes and defect assessment standards. Such models are sometimes referred to as limit state functions.

For damage that occurs instantaneously (and will either cause failure or it won't) these functions can be used to place bounds on the steady state operating regime. For instance recognising that internal pressure will affect the tolerability of most types of damage such functions can be used to determine the maximum allowable operating pressure. Managing the pressure is thus one means of ensuring that damage caused by external interference can be tolerated.

On the other hand, some types of damage (i.e. corrosion and construction defects) will not necessarily cause failure immediately but will become progressively more severe with time and cause failure in the future. Tolerance of this damage can either be ensured by preventing the growth and/or detecting the damage and removing and repairing it before it can cause failure. For instance some assurance of the initial sizes of construction defects is obtained from adherence to established construction processes and survival of the hydrostatic pressure test. The growth of such defects is controlled by controlling the magnitude of pressure fluctuations. On the other hand various steps are taken to prevent the occurrence of external corrosion. These include the application of a protective coating and the application of a cathodic protection system. However, it is generally found that external corrosion does occur and internal inspections and above ground surveys are used 
on a period basis to detect it. If corrosion is found the tolerability of it can be assessed based on the magnitude of the signal from the inspection/survey tool and action can be taken immediately or in the future based on an assessment its severity according to the limit state function.

From the above, a number of points emerges.

Firstly, the perceived severity of the damage that can be tolerated depends on the accuracy of limit state function and on the precision of the knowledge of the basic parameters such as wall thickness, material grade and operating pressure.

The true magnitude of any damage that has been found depends on the accuracy of the survey/inspection tools.

The likelihood of detecting the various types of damage depends on the reliability of the inspection and survey techniques. In general larger defects can be more reliably detected. There is thus an increased likelihood of detecting corrosion damage if it has been growing quicker or the inspection the interval between inspections is increased. However, larger defects are more likely to cause failure. It naturally follows that prevention of corrosion (and other types of damage) is the most steadfast means of integrity management. However, accepting this is rarely possible, the use of reliable tools at some optimum frequency is best substitute for this.

Another important issue is that, in general, there are more small construction defects earlier in life than there are larger defects. This means that in early life there are few defects requiring attention. However, as time increases and defects grow the number of defects requiring attention increases. This means that integrity management becomes more expensive as time increases. Similarly, as coating deteriorates with time the number of corrosion defects increases and management of corrosion becomes more expensive. This leads to the concept of economic life of the system. Depending on the revenue from transportation there necessarily comes a time when the cost of integrity management dictates that operation of the system is no longer economically viable and the life of the pipeline comes to an end.

The above narrative gives a brief description of integrity management and its relationship with asset (economic) life.

While integrity management and asset life have been described in principle, detail has thus far been neglected. However, based on the brief description given thus far it is clear that options for undertaking integrity management can be wide ranging. In the simplest form prescriptive integrity management can be undertaken following the guidelines of design codes. This will allow the operator to demonstrate compliance with legislation. However, due to the conservatism and shortcomings associated with prescriptive design codes, it likely that such an approach is expensive, does not capture all safety issues and perhaps will not allow operation beyond some nominal design life.

On the other hand, risk-based approaches that take account of many aspects of uncertainty may lead to reduced costs and a safer operating regime and may allow considerable extension of the economic life. The downside of the use of these techniques is that additional expertise is required and rigorous analytical tools are required to demonstrate the validity of the approach to regulators. Nonetheless the pay-back can be considerable in terms of both revenue and safety. 
The aim of this paper is to present and demonstrate robust techniques for combining the data from above ground surveys and ILI data to optimise the integrity management process and to extend the economic life of the a pipeline. A particular focus is given to ECDA.

External Corrosion Direct Assessment. ECDA has been proposed as a viable alternative to hydrostatic pressure testing and in-line inspection (ILI) for the purpose of managing the integrity of high pressure pipelines [1]. Accordingly, an ECDA standard is now in existence [2].

The essence of ECDA is to combine the results of two or more above ground surveys in order to establish a level of confidence in the condition of the pipeline. Recognising that all above ground survey techniques are subject to uncertainty, bell-hole excavations are performed to investigate the presence of damage at the locations of positive indications of the surveys and to allow any necessary repairs to be made using appropriate techniques. By repeating the process at sufficiently frequent intervals, the time dependent deterioration process due to external corrosion can be effectively managed.

A central issue associated with the use of above ground surveys is the uncertainty in their effectiveness. Notably, not all defects will be detected and at the locations of some indications no defect will be found. The characteristics of the surveys associated with these two issues are often referred to as the probability of detection (PoD) and the probability of false indication (PfI).

It thus follows that the data obtained from any above ground survey requires interpretation using probabilistic techniques. To this end, building on an outline approach given in [3], a detailed method has recently been developed [4] for determining the number of defects that are likely to be present based on the results of the particular survey and the values of the PoD and PfI. The method includes the effect of updating the distribution as information from excavations is acquired and accordingly determines when a sufficient level of integrity has been attained.

It is noteworthy, however, that such uncertainty is not confined only to above ground surveys. Inline inspection tools are also prone to such behavior.

In view of this, it follows that techniques used combining different above ground survey results can also be used to combine above ground survey results with ILI data.

Life Extension Using above Ground Survey Results. The approach adopted here is based on the concepts of ECDA.

ECDA is a four stage process is adopted. The four stages are referred to as:

1. Pre-assessment.

2. Indirect assessment.

3. Direct examination.

4. Post assessment.

Pre-assessment. During the pre-assessment stage, preliminary investigations are undertaken to determine whether the use of above ground survey techniques is viable. For instance, if a significant portion of the pipeline is buried under hard surfaces then DCVG would not be possible.

For the present purpose it is assumed that the surveys have been established, i.e., DCVG and CIPS and hence no further discussion of this aspect of the pre-assessment is required here. 
Nonetheless, another function of the pre-assessment is to establish the current condition of the pipe based on previously gathered data. This is discussed in more detail later

Indirect Assessment. The above ground surveys are undertaken during the indirect assessment stage. The purpose of these is to allow an initial updating of the prior distributions.

For the present purpose the two survey techniques are considered to be CIPS and DCVG.

Direct Examination. Above ground survey techniques are subject to uncertainty. The purpose of the direct examinations is to reduce uncertainty by providing direct information on the actual condition of the pipeline. The information obtained form direct examinations is used to improve the confidence in the performance characteristics of the above ground surveys and consequently to improve the confidence in the knowledge of the condition of the pipeline. This confidence is further enhanced by performing any necessary repairs during this phase.

Post Assessment. Once it has been established that the current integrity of the pipeline has been brought to an acceptable position, the data that have been obtained are used to determine the likely increase in the number of coating defects and the likely growth rates at locations of active corrosion. This information is used to determine the allowable time period before the next assessment will be necessary. In particular, for the present purpose, the future safe operational life is determined.

General Principle. The purpose of this section is to outline, through the use of basic formulations, how the four phases of the ECDA process are used to systematically achieve the objectives set out above.

The detail associated with the stated formulations is given later.

Pre-assessment. Based on the above, the prior condition of the pipeline is determined by the distribution of the number of corrosion defects, $p_{c 0}\left(N_{c}\right)$, and the defect depth distribution, $p_{0}(a)$. The latter will depend on the age of the pipeline, $t_{\text {age }}$, the time, $t_{i}$, at which corrosion growth commenced and the growth rate, $K$. Since the two latter quantities will be subject to uncertainty, the defect depth distribution can generally be expressed as

$$
p_{0}\left(a, t_{\text {age }}\right)=\int_{0}^{t_{\text {age }}} \int_{0}^{\infty} p\left(a, t_{\text {age }} \mid K, t_{i}\right) p_{0}(K) p_{0}\left(t_{i}\right) d K d t_{i}
$$

where $p_{0}(K)$ and $p_{0}\left(t_{i}\right)$ are the initial distributions of $K$ and $t_{i}$, respectively. The conditional probability, $p\left(a, t_{\text {age }} \mid K, t_{i}\right)$, depends on the growth process.

The above distribution allows the probability, $P\left(a_{r}, t_{\text {age }}\right)$, that any given defect will exceed the repair criterion to be determined and this quantity is given by

$$
P_{0}\left(a_{r}, t_{\text {age }}\right)=\int_{a_{r}}^{\infty} p_{0}\left(a, t_{\text {age }}\right) d a
$$


where all defects deeper than will be repaired. This is an important consideration for deciding when to terminate the ECDA investigation.

Indirect Assessment. Denoting the ILI run as survey $A$ and the DCVG survey as survey $B$, the most general outcome will be $N_{A B}$ locations at which both surveys give a positive indication, $N_{A}$ locations at which only survey $A$ gives a positive indication and $N_{B}$ locations at which only survey $B$ gives a positive indication.

The above quantities allow the expected number of coating defects $E_{H 0}$ and the expected number of corrosion defects, $E_{C 0}$, to be determined. In general these quantities will depend on the probability of detection and the probability of false indication of each of the surveys. It thus follows that $E_{H 0}$ and $E_{C 0}$ will have the functional forms,

$$
E_{H 0}=E_{H 0}\left(\zeta_{A 0}, \zeta_{B 0}, \phi_{A 0}, \phi_{B 0}, \alpha_{0}\right)
$$

and

$$
E_{C 0}=E_{C 0}\left(\zeta_{A 0}, \zeta_{B 0}, \phi_{A 0}, \phi_{B 0}, \alpha_{0}\right)
$$

where $\zeta_{A 0}, \zeta_{B 0}, \phi_{A 0}$, and $\phi_{B 0}$ are the probability of detection of survey $A$, the probability of detection of survey $B$, the probability of false indication of survey $A$, and the probability of false indication of survey $B$, respectively. The subscript ' 0 ' denotes conditions prior to any information from excavations being obtained. In the above $\alpha_{0}$ denotes the ratio of corrosion defects to coating defects. In order to evaluate the expressions given above, it is necessary to determine a value for $\alpha_{0}$. This can be achieved by finding the solution to the equation

$$
E_{C 0}\left(\zeta_{A 0}, \zeta_{B 0}, \phi_{A 0}, \phi_{B 0}, \alpha_{0}\right)=\alpha_{0} E_{H 0}\left(\zeta_{A 0}, \zeta_{B 0}, \phi_{A 0}, \phi_{B 0}, \alpha_{0}\right)
$$

Explicit reference to the dependence of $E_{H 0}$ and $E_{C 0}$ on $N_{A B}, N_{A}$, and $N_{B}$ has been omitted as these quantities are not subject to change.

The variance in the number of coating defects, $V_{H 0}$, and the variance in the number of corrosion defects, $V_{C 0}$, may also be obtained from the above ground survey results and consequently will take the functional forms

$$
V_{H 0}=V_{H 0}\left(\zeta_{A 0}, \zeta_{B 0}, \phi_{A 0}, \phi_{B 0}, \alpha_{0}\right)
$$

and

$$
V_{C 0}=V_{C 0}\left(\zeta_{A 0}, \zeta_{B 0}, \phi_{A 0}, \phi_{B 0}, \alpha_{0}\right)
$$

It follows that distributions of the number of coating and corrosion defects can be obtained and expressed in the general forms

$$
p_{H 0}\left(N_{H}\right)=p_{H 0}\left(N_{H}, E_{H 0}, V_{H 0}\right)=p_{H 0}\left(N_{N}, \zeta_{A 0}, \zeta_{B 0}, \phi_{A 0}, \phi_{B 0}, \alpha_{0}\right)
$$

and

$$
p_{C 0}\left(N_{H}\right)=p_{C 0}\left(N_{H}, E_{C 0}, V_{C 0}\right)=p_{C 0}\left(N_{C}, \zeta_{A 0}, \zeta_{B 0}, \phi_{A 0}, \phi_{B 0}, \alpha_{0}\right)
$$


Number of Corrosion Defects Exceeding Repair Criterion. The number of corrosion defects exceeding the repair criterion is related to the number of corrosion defects through

$$
N_{r C}=N_{C} P\left(a_{r}, t_{\text {age }}\right)
$$

from which it follows that the distribution, $p_{r C 0}$, of the number of defects, $N_{r C}$, exceeding the repair criterion is given by

$$
p_{r C 0}\left(N_{r C}\right)=\frac{1}{P_{0}\left(a_{r}, t_{a g e}\right)} p_{C 0}\left(\frac{N_{r C}}{P_{0}\left(a_{r}, t_{a g e}\right)}, \zeta_{A 0}, \zeta_{B 0}, \phi_{A 0}, \phi_{B 0}, \alpha_{0}\right)
$$

The above distribution has an expectation, $E_{r C 0}$, and variance, $V_{r C 0}$, given by

$$
E_{r C 0}=E_{C 0}\left(\zeta_{A 0}, \zeta_{B 0}, \phi_{A 0}, \phi_{B 0}, \alpha_{0}\right) P\left(a_{r}, t_{\text {age }}\right)
$$

and

$$
V_{r C 0}=V_{C 0}\left(\zeta_{A 0}, \zeta_{B 0}, \phi_{A 0}, \phi_{B 0}, \alpha_{0}\right) P\left(a_{r}, t_{\text {age }}\right)^{2}
$$

The above provide an initial view on the number of excavations that will be required.

Direct Examination. Updating the Distributions of $N_{H}$ and $N_{C}$. Excavations will generally be performed at some or all of the locations at which one or more of the surveys gave a positive indication. The outcome of the excavation will confirm whether or not a coating defect or a coating defect and a corrosion defect is present. This will allow the distributions of $N_{C}, N_{H}$, and $a$ to be updated.

The findings at each excavation will either be a corrosion defect, a coating defect with no corrosion or no coating defect.

This allows the values of $\alpha_{0}, \zeta_{A 0}, \zeta_{B 0}, \phi_{A 0}$, and $\phi_{B 0}$ to be updated. The nature of the updating depends on both the nature of the surveys and the nature of the findings and these issues are described in full detail later. However, at the present stage in this paper, it suffices to say that the results of the $M_{E}$ excavations, will result in the revised values $\alpha_{M_{E}}, \zeta_{A M_{E}}, \zeta_{B M_{E}}, \phi_{A M_{E}}$, and $\phi_{B M_{E}}$. The locations that are selected for excavation will have an effect on these values, however, the order in which the excavations are performed will not.

Based on the new values of $\alpha_{M_{E}}, \zeta_{A M_{E}}, \zeta_{B M_{E}}, \phi_{A M_{E}}$, and $\phi_{B M_{E}}$, the distributions of $N_{H}$ and $N_{C}$ can be updated giving

$$
\begin{gathered}
p_{H 0 M_{E}}\left(N_{H}\right)=p_{H 0}\left(N_{H}, E_{H M_{E}}, V_{H M_{E}}\right)= \\
=p_{H 0}\left(N_{H}, \zeta_{A M_{E}}, \zeta_{B M_{E}}, \phi_{A M_{E}}, \phi_{B M_{E}}, \alpha_{M_{E}}\right)
\end{gathered}
$$

and

$$
p_{C 0 M_{E}}\left(N_{C}\right)=p_{C 0}\left(N_{C}, E_{C M_{E}}, V_{C M_{E}}\right)=
$$




$$
=p_{C 0}\left(N_{C}, \zeta_{A M_{E}}, \zeta_{B M_{E}}, \phi_{A M_{E}}, \phi_{B M_{E}}, \alpha_{M_{E}}\right)
$$

Note from the above that the functional form of the distributions has not changed; the change is only to the characterising parameters.

In addition to causing the characteristic parameters to change, if $M_{H}$ coating defects are found (with or without corrosion) and $M_{C}$ corrosion defects are found, then a further modification to the distributions is appropriate resulting in

$$
\begin{gathered}
p_{H M_{E} M_{E}}\left(N_{H}, \zeta_{A M_{E}}, \zeta_{B M_{E}}, \phi_{A M_{E}}, \phi_{B M_{E}}, \alpha_{M_{E}}\right)= \\
=\frac{p_{H 0}\left(N_{H}, \zeta_{A M_{E}}, \zeta_{B M_{E}}, \phi_{A M_{E}}, \phi_{B M_{E}}, \alpha_{M_{E}}\right) H\left(N_{H}-M_{H}\right)}{\int_{M_{H}}^{\infty} p_{H 0}\left(N_{H}, \zeta_{A M_{E}}, \zeta_{B M_{E}}, \phi_{A M_{E}}, \phi_{B M_{E}}, \alpha_{M_{E}}\right) d N_{H}}
\end{gathered}
$$

and

$$
\begin{gathered}
p_{C M_{E} M_{E}}\left(N_{C}, \zeta_{A M}, \zeta_{B M_{E}}, \phi_{A M_{E}}, \phi_{B M_{E}}, \alpha_{M_{E}}\right)= \\
=\frac{p_{C 0}\left(N_{C}, \zeta_{A M_{E}}, \zeta_{B M_{E}}, \phi_{A M_{E}}, \phi_{B M_{E}}, \alpha_{M_{E}}\right) H\left(N_{C}-M_{C}\right)}{\int_{M_{C}}^{\infty} p_{C 0}\left(N_{C}, \zeta_{A M_{E}}, \zeta_{B M_{E}}, \phi_{A M_{E}}, \phi_{B M_{E}}, \alpha_{M_{E}}\right) d N_{C}},
\end{gathered}
$$

where $H(\cdot)$ denotes the Heaviside step function.

Distribution of Numbers of Remaining Defects. The numbers of remaining coating defects, $N_{H R}$, and corrosion defects, $N_{C R}$, are given by

$$
N_{H R}=N_{H}-M_{H}
$$

and

$$
N_{C R}=N_{C}-M_{C}
$$

from which it follows that the distributions of remaining defects are given by

$$
\begin{gathered}
p_{H M_{E} M_{E} R}\left(N_{H R}, \zeta_{A M_{E}}, \zeta_{B M_{E}}, \phi_{A M_{E}}, \phi_{B M_{E}}, \alpha_{M_{E}}\right)= \\
=\frac{p_{H 0}\left(N_{H R}+M_{H}, \zeta_{A M_{E}}, \zeta_{B M_{E}}, \phi_{A M_{E}}, \phi_{B M_{E}}, \alpha_{M_{E}}\right)}{\int_{0}^{\infty} p_{H 0}\left(N_{H R}+M_{H}, \zeta_{A M_{E}}, \zeta_{B M_{E}}, \phi_{A M_{E}}, \phi_{B M_{E}}, \alpha_{M_{E}}\right) d N_{H R}}
\end{gathered}
$$

and

$$
p_{C M_{E} M_{E} R}\left(N_{C R}, \zeta_{A M_{E}}, \zeta_{B M_{E}}, \phi_{A M_{E}}, \phi_{B M_{E}}, \alpha_{M_{E}}\right)=
$$




$$
=\frac{p_{C 0}\left(N_{C R}+M_{C}, \xi_{A M_{E}}, \zeta_{B M_{E}}, \phi_{A M_{E}}, \phi_{B M_{E}}, \alpha_{M_{E}}\right)}{\int_{0}^{\infty} p_{C 0}\left(N_{C R}+M_{C}, \xi_{A M_{E}}, \zeta_{B M_{E}}, \phi_{A M_{E}}, \phi_{B M_{E}}, \alpha_{M_{E}}\right) d N_{C R}} .
$$

Updating the Distribution of $a$. Following the $M_{E}$ excavations and the discovery of $M_{C}$ corrosion defects, it is also possible to update the corrosion defect depth distribution. This is done by updating the distributions of $K$ and $t_{i}$.

The joint distribution of $K$ and $t_{i}$ is updated using the expression it

$$
p_{M_{E}}\left(K, t_{i}\right)=\frac{\prod_{j=1}^{M_{C}} p\left(a_{j}, t_{\text {age }} \mid t_{i}, K\right) p_{K 0}(K) p_{t i 0}\left(t_{i}\right)}{\int_{0}^{t_{\text {age }}} \int_{0}^{\infty} \prod_{j=1}^{M_{C}} p\left(a_{j}, t_{\text {age }} \mid t_{i}, K\right) p_{K 0}(K) p_{t i 0}\left(t_{i}\right) d K d t_{i}},
$$

where the $a_{i}$ values $\left(j=1\right.$ to $M_{C}$ ) are the measured depths of the corrosion defects found at the excavations. If follows that the updated defect depth distribution is given by

$$
p_{M_{E}}\left(a, t_{\text {age }}\right)=\int_{0}^{t_{\text {age }}} \int_{0}^{\infty} p\left(a, t_{\text {age }} \mid K, t_{i}\right) p_{M_{E}}\left(K, t_{i}\right) d K d t_{i} .
$$

Naturally, the above distribution will depend on the results of excavations that have been undertaken, however, it will be independent of the order in which the excavations are undertaken.

Distribution of Number of Remaining Corrosion Defects Exceeding the Repair Criterion. The probability that any single defect depth will exceed the repair criterion after $M_{E}$ excavations have been undertaken is given by

$$
P_{M_{E}}\left(a_{r}, t_{\text {age }}\right)=\int_{a_{r}}^{\infty} p_{M_{E}}\left(a, t_{\text {age }}\right) d a .
$$

The number of remaining corrosion defects exceeding the repair criterion, $N_{r C R}$, is then given by

$$
N_{r C R}=N_{C R} P_{M_{E}}\left(a_{r}, t_{\text {age }}\right) .
$$

It then follows that the distribution, $p_{r C M_{E} M_{E} R}\left(N_{r C R}\right)$, of the number of remaining defects, $N_{r C R}$, exceeding the repair criterion is given by

$$
p_{r C M_{E} M_{E} R}\left(N_{r C R}\right)=\frac{1}{P_{M_{E}}\left(a_{r}, t_{\text {age }}\right)} p_{C M_{E} M_{E} R}\left(\frac{N_{r C R}}{P_{M_{E}}\left(a_{r}, t_{\text {age }}\right)}\right) .
$$


The above distribution has an expectation, $E_{r C M_{E} M_{E} R}$, and variance, $V_{r C M_{E} M_{E} R}$, given by

$$
E_{r C M_{E} M_{E} R}=E_{C M_{E} M_{E} R}\left(a_{r}, t_{\text {age }}\right)
$$

and

$$
V_{r C M_{E} M_{E} R}=V_{C M_{E} M_{E} R} P_{M_{E}}\left(a_{r}, t_{\text {age }}\right)^{2},
$$

respectively, where $E_{C M_{E} M_{E} R}$ and $V_{C M_{E} M_{E} R}$ are the expectation and variance associated with $p_{C M_{E} M_{E} R}\left(N_{C}\right)$.

The general principle outlined above applies to any ECDA methodology and therefore represents a general framework for reference.

Example. The intent of this section is to show, using a simple example, how the methodology can be used as part of an integrity management program to extend the pipeline life.

Pre-assessment. The pipeline parameters used in this example are given in Table 1. It should be noted that since the methodology described in this paper requires only knowledge of the repair depth, there is no requirement to detail all the pipeline parameters.

$\mathrm{T}$ a b 1 e 1

Pipeline Parameters

\begin{tabular}{|c|c|}
\hline Parameter & Value \\
\hline Commissioning year & 1970 \\
\hline Current year & 2006 \\
\hline Diameter & $219.1 \mathrm{~mm}$ \\
\hline Wall thickness & $6.35 \mathrm{~mm}$ \\
\hline Grade & $\mathrm{X} 42$ \\
\hline Pressure & $5.5 \mathrm{MPa}$ \\
\hline Repair depth & $30 \%$ wall thickness \\
\hline Number of corrosion defects & 10 \\
\hline
\end{tabular}

In order to calculate the defect depth distribution, the distributions in Table 2 have been used to model the uncertainty in the above three parameters.

The distribution of initiation depth is assumed to represent those defects that are just becoming detectable, i.e., smaller defects are not considered to be defects. This assumption is acknowledged as being subjective; however, it suffices here for the purpose of illustration.

The initiation time is perhaps subject to most uncertainty in practice and indeed this quantity has rarely been isolated and indeed may have an effect on reported measured growth rates. It is acknowledged that more focus is needed on the determination of this quantity, and the values used below, whilst not unrealistic are used only for illustration purposes here. 
Pipeline Life Extension and Integrity Management ...

$\mathrm{T}$ a b 1 e 2

Distributions Used in Defect Depth Distribution

\begin{tabular}{|c|c|c|c|}
\hline Factor & Distribution & Mean & Standard deviation \\
\hline Initiation depth & Weibull & $0.5 \mathrm{~mm}$ & $0.5 \mathrm{~mm}$ \\
\hline Initiation time, $t_{i}$ & Normal & 18 years & 4 years \\
\hline Growth rate, $K$ & Normal & $0.2 \mathrm{~mm}$ per year & $0.025 \mathrm{~mm}$ per year \\
\hline
\end{tabular}

Using the data given above, the defect depth of the 36 year old pipeline was determined using Eq. (1) and the results are shown graphically in Fig. 1. It is seen from Fig. 1 that the mean depth increases from $0.5 \mathrm{~mm}$ to about $1.75 \mathrm{~mm}$ in the 36 year period based on an average growth rate of $0.2 \mathrm{~mm}$ per year. At first glance this result appears anomalous. However, it is important to note that not all defects will have been growing for the full 18 year period. Those defects introduced towards the end of the 36 year period will have been growing for a very short time and this is reflected in the results given in Fig. 1.

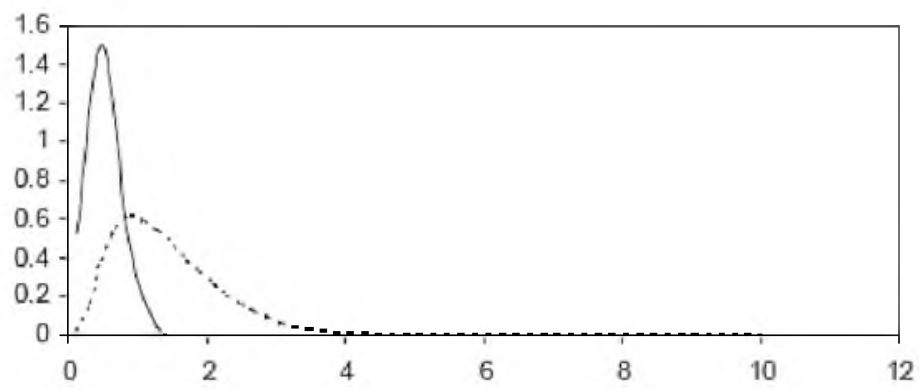

Fig. 1: Defect depth distribution (solid line correspond initiation distribution; dashed line - 2006 distribution).

Using the defect depth distribution and Eq. (2), it is possible to make an initial assessment of the condition of the pipeline. The probability that any given defect will exceed the failure criterion, given in Table 1 , is 0.235 . This means, using (12), that the expected number of corrosion defects exceeding the repair criterion is around 2.35 .

Structural Reliability Analysis (SRA) can be used to determine the future failure probability for the pipeline. Details of the approach used can be found in [3]. The failure probability for the pipeline is shown in Fig. 2. It can be seen that in 2010 (40 year design life) the failure probability is marginally greater than $1.0 \cdot 10^{-3}$ per $\mathrm{km}$. Based on AFAA's experience of conducting similar studies this figure is considered high, although a more extensive study would look at the risks associated with this failure probability.

Indirect Assessment. The number of indications from the Corrosion Survey and DCVG survey is given in Table 3.

From Table 3, it can be seen that there were five areas where both the Corrosion Survey (survey $A$ ) and the DCVG (survey $B$ ) were positive, no areas where only the Corrosion survey was positive and twenty-five areas where only the coating survey was positive. 
$\mathrm{T}$ a b 1 e 3

Above Ground Survey Results

\begin{tabular}{|c|c|}
\hline Indication type & Number of indications \\
\hline$N_{A B}$ & 5 \\
\hline$N_{A}$ & 0 \\
\hline$N_{B}$ & 25 \\
\hline
\end{tabular}

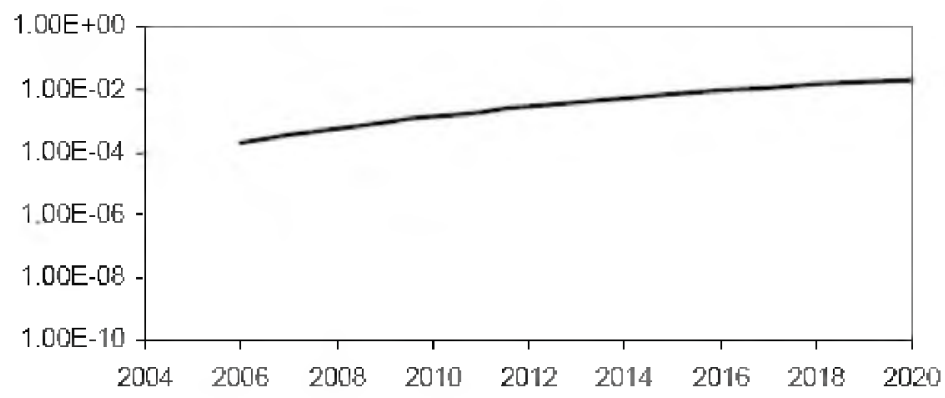

Fig. 2. Future failure probability based on pre-assessment information.

For the purposes of this example, the mean values of the probability of detection $(\zeta)$ and probability of false indication $(\phi)$ of the above ground surveys $A$ and $B$ are given by Table 4 .

$\mathrm{T}$ a b 1 e 4

Above Ground Survey Characteristics

\begin{tabular}{|c|c|c|}
\hline Probability & ILI (survey $A$ ) & DCVG (survey $B$ ) \\
\hline Probability of detection & 0.76 & 0.84 \\
\hline Probability of false indication & 0.10 & 0.11 \\
\hline
\end{tabular}

These values are based on previous comparisons between indicated and observed results on earlier projects. However, it is likely that different values will be appropriate to other situations and hence the values given here should be regarded as indicative only. Notwithstanding this, the updating will cause a migration of the initial starting values towards the true values in any given situation.

The distributions for the number of corrosion defects and the number of coating holidays are shown in Fig. 3.

The expected number of corrosion defects after the indirect assessment is 6.6. Using (12), the probability of a single defect exceeding the repair criterion is 0.235 and the expected number of corrosion defects exceeding the repair criterion is 1.55 . So after the indirect assessment there has been a decrease in the number of corrosion defects exceeding the repair criterion, this is due to the updating of the number of corrosion defects based on the above ground survey results, taking account of the accuracy of the above ground techniques. 


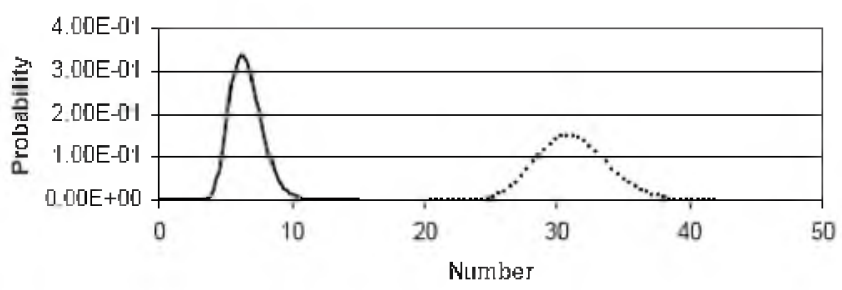

Fig. 3. Distribution of corrosion defects and coating holidays after indirect assessment (dots correspond coating holidays; solid line - corrosion defects).

Direct Examination. Excavations, based on the results of the above ground surveys, are undertaken during the direct examination stage. The purpose of these is to allow us to update our view on the accuracy of the above ground surveys, the number of corrosion defects on the pipeline, the size of corrosion defects on the pipeline and hence the number of corrosion defects that exceed the repair criterion.

For this example, it has been assumed that twenty excavations have been undertaken. Five of the excavations were carried out at areas where both surveys were positive; at each of these excavations, a coating holiday and corrosion were found.

Fifteen excavations were carried out at sites where the coating survey was positive; at each of these excavations a coating holiday with no corrosion was found. The sequential changes to the characteristics of the above ground surveys are shown in Table 5.

From Table 5, it can be seen that the probability of detection of the corrosion survey $\left(\zeta_{A}\right)$ increases (i.e., survey is more accurate) from 0.76 to 0.79 , this is due to the fifteen excavations where the corrosion survey was negative and no corrosion was found. The probability of false indication of the corrosion survey $\left(\phi_{A}\right)$ and the probability of detection of the coating survey $\left(\zeta_{B}\right)$ are unchanged as there have been no excavations where the corrosion survey was positive and the coating survey was negative. In the final column of Table 5 , it can be seen that the probability of false indication of the coating survey $\left(\phi_{B}\right)$ decreases (i.e., survey is more accurate) from 0.11 to 0.09 . Again, this is due to excavating fifteen locations where the coating survey was positive and a coating holiday was found at each excavation.

The change in number of corrosion defects and the number of remaining corrosion defects is shown in Table 6 and Fig. 4.

From Table 6 and Fig. 4 it is seen that the overall expected number of corrosion defects decreases slightly. This is due to an increase in the probability of detection of the Corrosion Survey, i.e., the corrosion survey is less prone to missing defects.

In this case, the expected number of remaining unknown corrosion defects again decreases in direct accordance with the total number; the difference being generally due to the 5 known corrosion defects found at sites where both surveys were positive.

Since corrosion defects were found during the excavations, it is also possible to update the initiation time and growth rate distributions, which in turn allows us to update the defect depth distribution. The depths of corrosion defects found during the excavations are shown in Table 7. 
$\mathrm{T}$ a b 1 e 5

Effect of Excavations on Survey Characteristics

\begin{tabular}{|c|c|c|c|c|}
\hline Excavation & $\zeta_{A}$ & $\phi_{A}$ & $\xi_{B}$ & $\phi_{B}$ \\
\hline 0 & 0.76 & 0.10 & 0.84 & 0.11 \\
\hline 1 & 0.76 & 0.10 & 0.84 & 0.11 \\
\hline 2 & 0.76 & 0.10 & 0.84 & 0.11 \\
\hline 3 & 0.76 & 0.10 & 0.84 & 0.11 \\
\hline 4 & 0.76 & 0.10 & 0.84 & 0.11 \\
\hline 5 & 0.76 & 0.10 & 0.84 & 0.11 \\
\hline 6 & 0.76 & 0.10 & 0.84 & 0.11 \\
\hline 7 & 0.76 & 0.10 & 0.84 & 0.11 \\
\hline 8 & 0.77 & 0.10 & 0.84 & 0.10 \\
\hline 9 & 0.77 & 0.10 & 0.84 & 0.10 \\
\hline 10 & 0.77 & 0.10 & 0.84 & 0.10 \\
\hline 11 & 0.77 & 0.10 & 0.84 & 0.10 \\
\hline 12 & 0.78 & 0.10 & 0.84 & 0.10 \\
\hline 13 & 0.78 & 0.10 & 0.84 & 0.10 \\
\hline 14 & 0.78 & 0.10 & 0.84 & 0.10 \\
\hline 15 & 0.78 & 0.10 & 0.84 & 0.10 \\
\hline 16 & 0.78 & 0.10 & 0.84 & 0.10 \\
\hline 17 & 0.79 & 0.10 & 0.84 & 0.09 \\
\hline 18 & 0.79 & 0.10 & 0.84 & 0.09 \\
\hline 19 & 0.79 & 0.10 & 0.84 & 0.09 \\
\hline 20 & 0.79 & 0.10 & 0.84 & 0.09 \\
\hline
\end{tabular}

Change in Expected Number of Corrosion Defects

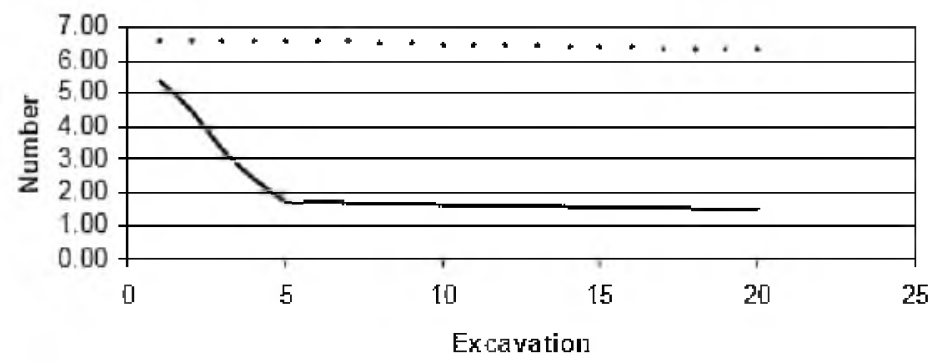

Fig. 4. Effect of excavations on the expected number of corrosion defects and number of corrosion defects remaining (dots correspond expected number of corrosion defects; solid line - expected number of remaining corrosion defects).

The effect of the corrosion defects found during excavations on the defect depth is shown in Fig. 5. From Fig. 5 it can be seen that the there is a gradual shift to the left, i.e., excavations are saying that the depth of corrosion defects are not as deep as was thought during the pre-assessment. This could be due to the initial corrosion growth rate being too high, the time corrosion defects initiate being too early or a combination of both of these. 
$\mathrm{T}$ a b 1 e 6

Effect of Excavations on Expected Number of Corrosion Defects and Number of Corrosion Defects Remaining

\begin{tabular}{|c|c|c|}
\hline Excavation & $E_{C}$ & $E_{C R}$ \\
\hline 1 & 6.59 & 5.39 \\
\hline 2 & 6.59 & 4.49 \\
\hline 3 & 6.59 & 3.29 \\
\hline 4 & 6.59 & 2.42 \\
\hline 5 & 6.59 & 1.74 \\
\hline 6 & 6.57 & 1.72 \\
\hline 7 & 6.55 & 1.70 \\
\hline 8 & 6.53 & 1.69 \\
\hline 9 & 6.50 & 1.67 \\
\hline 10 & 6.48 & 1.65 \\
\hline 11 & 6.47 & 1.64 \\
\hline 12 & 6.45 & 1.62 \\
\hline 13 & 6.43 & 1.60 \\
\hline 14 & 6.41 & 1.59 \\
\hline 15 & 6.39 & 1.57 \\
\hline 16 & 6.38 & 1.56 \\
\hline 17 & 6.36 & 1.55 \\
\hline 18 & 6.34 & 1.53 \\
\hline 19 & 6.33 & 1.52 \\
\hline 20 & 6.31 & 1.51 \\
\hline
\end{tabular}

$\mathrm{T}$ a b 1 e 7

Depth of Corrosion Defects Found During Excavations

\begin{tabular}{|c|c|}
\hline Excavation & Corrosion depth $(\mathrm{mm})$ \\
\hline 1 & 1.2 \\
\hline 2 & 1.0 \\
\hline 3 & 0.9 \\
\hline 4 & 1.1 \\
\hline 5 & 1.0 \\
\hline
\end{tabular}

The effect of the above ground surveys and the excavations on the expected number of corrosion defects exceeding the repair criterion is shown in Fig. 6.

From Fig. 6, it can be seen that there is a steady drop in the expected number of corrosion defects greater than the repair criterion.

Based on the expected number of corrosion defects greater than the repair criterion, a decision can be made on whether further excavations are required. For the purposes of this example, it is assumed that excavations are necessary until this value is $5 \%$ or less (highlighted by the bold line in Fig. 6). Thus on this occasion, it would be appropriate to stop excavating after 5 excavations. 


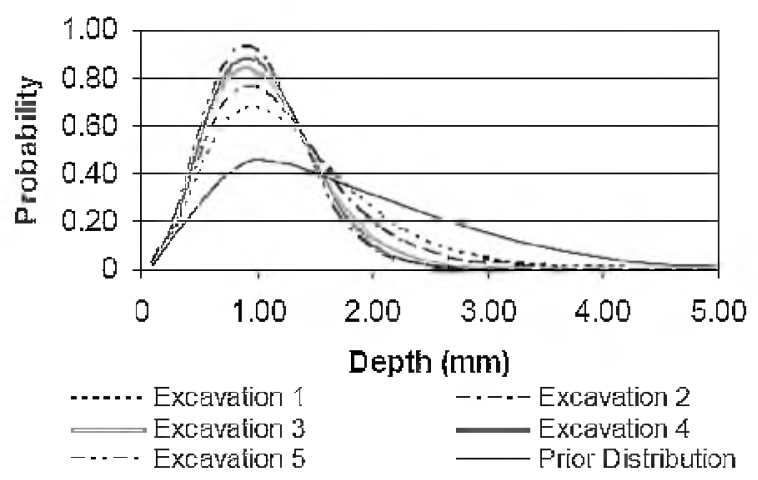

Fig. 5. Effect of excavated corrosion defects on the defect depth distribution.

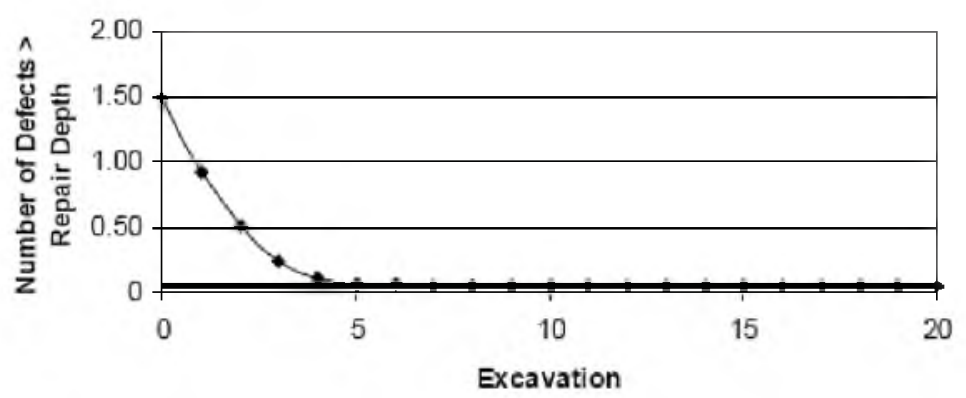

Fig. 6. Effect of excavations on the expected number of defects greater than the repair depth.

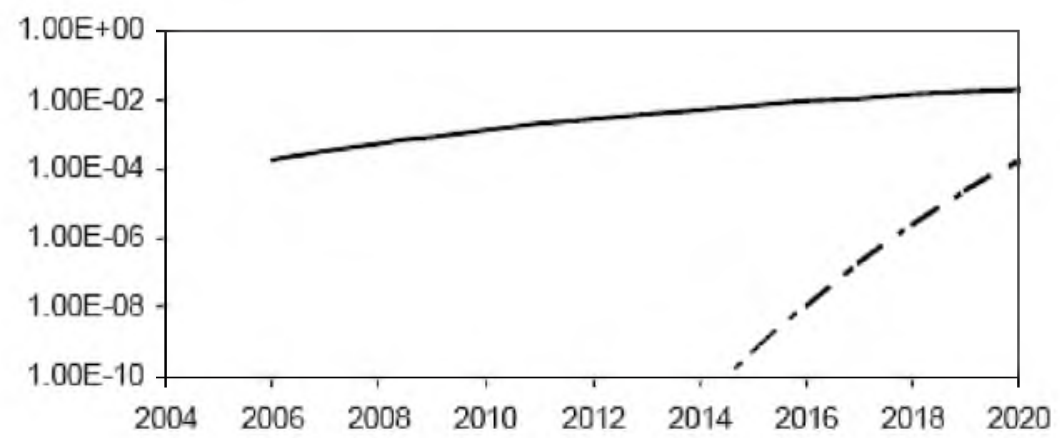

Fig. 7. Comparison of pre- (solid line) and post-assessment (dashed line) failure probability.

Post Assessment and Life Extension. The post assessment stage uses the updated distributions for the defect depth and number determined in the indirect and direct examination stages to determine an updated failure probability for the pipeline. This failure probability can be used to determine the date for the next integrity assessment or in this example to be used to determine the length of life extension possible.

SRA was used to determine the failure probability based on the updated distributions.

The updated failure probabilities are shown in Fig. 7 for the time period between 2006 and 2020. It is immediately obvious that using the information gathered from the above ground surveys and the excavations that the failure 
probability due to external corrosion has reduced to negligible values up to around 2010. Furthermore, assuming an acceptable failure probability of around $1.0 \cdot 10^{-4}$ per $\mathrm{km}$, it can be seen that the failure probability remains acceptably low until around 2020.

Based on the above, the ECDA methodology has shown that probability of failure remains acceptable till around 2020. The implications of this outcome are that it is possible to schedule future integrity assessments, but it is also viable to consider extending the life of the pipeline beyond the 40 year nominal design life.

\section{Conclusions}

1. The following methods have been presented:

- a method for determining the corrosion defect depth distribution based on variable growth rate, variable growth time, and time dependent introduction of corrosion defects;

- a method for determining the expected number of coating defects, the expected number of corrosion defects, the associated variances, and hence the distributions, based on the results from a coating survey and a Corrosion survey;

- a method for updating the corrosion defect distribution based on the measurements made at excavations;

- a method for simultaneously updating the probability of detection and the probability of false indication of each survey technique based on the results from excavations;

- a method for updating the distributions of the numbers of coating and corrosion defects based on the results from excavation;

- a method for determining the distribution of the number of remaining defects following excavation and repair;

- a method for determining the expected number of defects that will exceed the repair criteria and the confidence limits on this quantity.

2. A simple example showing how the method is used to extend the life of ageing pipelines has been presented.

\section{Резиме}

Детально описано ймовірнісні методики, що базуються на обновленні даних за Байесом і розрахунку надійності конструкцій. Методики використовуються для оптимізації діагностичного огляду і (або) частоти проведення локальних інспекцій трубопроводів. Це гарантує економічний розв'язок проблем забезпечення працездатності трубопроводів, подовження їх довговічності чи оптимізації тиску в них. Суть запропонованої методики й особливості їі використання описано на різних прикладах.

1. US Code of Federal Regulations (CFR) Title 49. "Transportation of Hazardous Liquids by Pipeline," Part 195. Washington, DC.

2. NACE Recommended Practice RP0502-2002, Pipeline External Corrosion Direct Assessment. 
3. A. Francis, M. Gardiner, A. Goodfellow, et al., "A systematic risk and reliability-based approach to integrity management of piggable and nonpiggable pipelines," Pipeline Integrity and Safety Conference, Houston (2001).

4. A. Francis and C. Jandu, "Optimized ECDA based on simultaneous interpretation of multiple above ground survey techniques and identification of required excavation sites using a probabilistic methodology," NACE 2006, San Diego (2006).

Received 05. 01. 2009 